\title{
Operativizando la relación ley-reglamento: una propuesta de redefinición del rol de la reserva legal
}

\author{
Matías Guiloff Titiun*
}

\begin{abstract}
RESUMEN
Tomando en consideración el rol de la legislación y la administración en la actualidad, el presente trabajo explica por qué y para qué es necesario redefinir la reserva de ley. Esa redefinición pasa por operativizar la colaboración ley-reglamento, encauzando así su articulación a través de determinados medios, lo cual no es incompatible con la normativa constitucional; sin embargo, ello requiere modificar la manera en que el tribunal constitucional se aproxima a los casos de reserva legal.
\end{abstract}

$$
\text { Reserva de ley - estructura de la legislación - reglamento }
$$

\section{Making operative the relationship between legislation and administrative rulemaking: a redefinition proposal for the legal reserve clause}

\begin{abstract}
Considering the current role of both legislation and administrative rulemaking, this paper argues why and for what purposes it is necessary to redefine the understanding of legal reserve clause. Such redefinition regards making operative the legislation-administrative rulemaking relationship, by channeling it through certain means. It is not incompatible with the Chilean Constitution, though it requires that the constitutional court changes its approach to legal reserve cases.
\end{abstract}

Legal reserve clause - legislation structure - administrative rules

\footnotetext{
* Abogado, Profesor de Derecho Administrativo e Investigador del Programa de Derecho y Política Ambiental en la Facultad de Derecho de la Universidad Diego Portales, Santiago de Chile. Correo electrónico: matias.guiloff@udp.cl. Este trabajo forma parte del Proyecto Fondecyt Regular $N^{\circ} 1110376$ (2011-2012) titulado "La reserva de ley como límite del legislador democrático y la necesidad de redefinir su función en el Estado Constitucional chileno", del que su autor es coinvestigador.

Artículo recibido el 30 de marzo de 2012 y aceptado para su publicación por el Comité Editorial el 31 de mayo de 2012.
} 


\section{INTRODUCCIÓN}

$\mathrm{T}$ res son los grandes temas en materia de la relación ley-reglamento en el sistema constitucional chileno. El primero se refiere a si acaso este último contempla un dominio legal máximo; o, por el contrario, manteniendo la opción de la Constitución Política de 1925, establece uno mínimo ${ }^{1}$. El segundo se refiere a si el reglamento puede o no intervenir en la regulación de las materias sujetas a reserva y, en caso de ser afirmativa la respuesta, cuáles son los límites a los que debe sujetarse su intervención ${ }^{2}$. El tercero-que se ha planteado como un problema de constitucionalidad sólo en el último tiempo ${ }^{3}$ - es el relativo a la potestad normativa de los órganos descentralizados y autónomos ${ }^{4}$. El presente artículo se centra únicamente en el segundo, pero dado el propósito que lo motiva, que no es otro que darle operatividad al Reglamento, lo hace desde una perspectiva amplia, incorporando al análisis la situación del reglamento autónomo.

La razón para ello radica en una cierta insatisfacción con la manera en que nuestra comunidad jurídica se ha aproximado a esa cuestión. Para buena parte de ella, Ley y Reglamento son categorías que se analizan por separado, teniendo cada una de ellas su ámbito de actuación bien determinado por el artículo 63 de la Constitución Política. Es decir, se trata de una aproximación bastante formal, para la cual los aspectos funcionales

${ }^{1}$ Ver Bulnes, L., "Leyes de base y potestad reglamentaria en la Constitución de 1980", en Revista de Derecho de la Universidad Católica de Valparaíso, vol. 6, 1982, pp. 136 y 137; Cea, J. L., "Dominio legal y reglamentario en la Constitución de 1980", en Revista Chilena de Derecho, vol. 11, 1984, p. 431; Ribera, T., "Reserva legal y potestad reglamentaria en la Constitución de 1980”, en Revista de Derecho Público, vol. 63, 2001, pp. 179 y siguientes; García, G., La reserva legal de derechos constitucionales: ¿Poder legislativo contra la Administración?, en Colección de Investigaciones Jurídicas Universidad Alberto Hurtado, 2004, pp. 118-123; Cazor, K., "Nuevo artículo $93 \mathrm{~N}^{\circ}$ 16: Un enfoque más coherente en torno al control de los decretos supremos por parte del Tribunal Constitucional", en Zúñiga F. (coord.), Reforma constitucional, LexisNexis, Santiago, 2005, p. 404, y Cordero, E., "El sentido actual del dominio legal y la potestad reglamentaria", en Revista de Derecho de la Universidad Católica de Valparaíso, vol. 32, 2009, p. 433.

2 Ver Rajevic E., "Limitaciones, reserva legal y contenido esencial de la propiedad privada", en Revista Chilena de Derecho, vol. 23, N 1, pp. 33-35; Carmona, C., "Un nuevo estadio en la relación ley-reglamento", en Revista de Derecho Público, vol. 63, p. 183; García, G., La reserva legal de derechos constitucionales: ¿Poder legislativo contra la Administración?, en Colección de Investigaciones Jurídicas Universidad Alberto Hurtado, 2004, pp. 158 y ss; Pierry, P., "El ámbito de la ley", en AA.VV, Proceso Legislativo en Chile, CEAL-UCV, Valparaíso, 1991, p. 82, y Cordero, L., "Entre la deferencia, los estándares de control judicial y los procedimientos administrativos. Comentarios a las sentencias sobre el caso Celco", en Revista de Derecho Público, vol. 67, pp. 448-449.

3 Por todos, Aldunate, E., "La distribución de potestades normativas en la Constitución: potestades reglamentarias administrativas, autos acordados y facultades del fiscal nacional", en Revista de Derecho de la Universidad Católica de Valparaíso, pp. 374-375. En contra, Cordero, E., "Las normas administrativas y el sistema de fuentes", en Revista de Derecho Universidad Católica del Norte, año 17, N 1, pp. 41-42.

${ }^{4}$ Existe doctrina respecto al carácter y los límites de la potestad normativa de estos órganos, que en ningún momento plantea un problema de constitucionalidad sobre la misma. Ver Silva, E., Derecho Administrativo Chileno y Comparado. Introducción y fuentes, Editorial Jurídica, Santiago, Cuarta Edición, p. 178; Moraga, C., "La actividad formal de la administración del Estado", en Rolando Pantoja Bauzá (Coord), Tratado de Derecho Administrativo Tomo VII, Rolando Pantoja Bauzá (Coord), p. 50. 
parecen ser irrelevantes, lo que acarrea consecuencias para la manera en que se conciben ambas fuentes.

Mientras a la ley, justificadamente, se la ve como un producto jurídico totalmente inmaculado, al reglamento, en cambio y por alguna razón, se lo ve como uno degradado. Ello resulta problemático, si se considera que en muchas instancias el reglamento entra en acción justamente porque la ley, a través del mismo, pretende asegurar el cumplimiento de sus objetivos. Más aún, en aquellas instancias donde la realidad ilustra situaciones que hasta entonces no se habían divisado por parte del ordenamiento jurídico, es ese instrumento "degradado" el que permite que se establezca algún tipo de regulación a la misma. Es cierto, ese "degradado" producto jurídico se puede prestar para usos abusivos; pero el abuso no puede ni debe hacer perder de vista otros tantos buenos usos que se le pueden dar. De ahí surge la principal intención de este artículo: operativizar la colaboración ley-reglamento.

Desde esa perspectiva, propongo una redefinición de la reserva de ley, que pasa porque ésta encauce la colaboración entre Ley y Reglamento. Para este propósito, comenzaré refiriéndome al rol que juegan en la actualidad la Ley y el Reglamento, enfatizando el carácter no transitivo de una buena parte de la legislación que hoy se dicta y aludiendo a cómo ello modifica la manera en que tradicionalmente se ha caracterizado al rol de la Administración. En atención a esa realidad es que este artículo, en su segunda parte, propondrá una redefinición de la reserva de ley en los términos antes mencionados, señalando una serie de medios que pueden ser utilizados, de abrazarse dicha redefinición, y justificando la plena compatibilidad de la misma con la Constitución. Por último, la sección se referirá a las implicancias para la adjudicación constitucional de adoptar la redefinición de la reserva de ley en los términos propuestos; en particular, a cómo ésta deberá variar su manera de aproximarse a los casos de reserva legal en el futuro.

\section{El ROL DE LA LEGISLACIÓN Y LA POTESTAD REGLAMENTARIA EN LA ACTUALIDAD}

El propósito de esta sección es demostrar que los roles que cumplen en la actualidad la legislación y el reglamento deben incidir en la manera en que se define la reserva de ley. Para ello describiré cómo la estructura de la legislación ha mutado para un efectivo cumplimiento de sus fines. Asimismo, plantearé cómo ha cambiado la función de la administración y la incidencia de ello sobre la extensión de sus potestades reglamentarias autónoma y de ejecución. Al respecto, cabe señalar que una razonable explicación de las mutaciones que han experimentado ambas funciones viene dada por el uso recurrente de la legislación no transitiva por parte del legislador, en procura de lograr una mayor efectividad de la ley. Estos cambios, como se argumentará en la siguiente sección, hacen necesario redefinir la función de la reserva de ley. 


\subsection{La legislación y sus grados de transitividad}

La actual, se dice, es una sociedad de riesgos ${ }^{5}$, en la cual se requieren respuestas dinámicas, incidiendo dicha característica sobre la legislación que se dicta para tener efectos en ella. En una sociedad de estas características se requieren respuestas rápidas ante complejos problemas de política pública. Sin embargo, al legislador se le hace imposible ser autónomo en ese escenario, pues se le presenta un dilema: ¿cómo mantener el rol de dirección de la política pública sin que por ello pierda la capacidad de responder rápidamente cuando las circunstancias así lo ameriten? Alguien, claro está, tendrá que tomar una decisión frente a hechos concretos y la pregunta relevante, en este sentido, es cuánto quiere influir el legislador sobre ella. Como se explicará a continuación, el legislador, sin decir al ejecutor precisamente qué es lo que corresponde realizar, puede influir significativamente sobre esa decisión, estructurando la respectiva ley de manera tal que ésta preserve el grado de flexibilidad necesario para adecuarse a las específicas circunstancias de hecho que se presenten al momento de implementarla.

De acuerdo a lo anterior, y dadas las limitaciones institucionales que presenta el legislador para hacerse cargo de manera directa e integral de los problemas de política pública, la atribución de potestades normativas a la administración, a través de lo que se denomina legislación no transitiva, es inevitable. Como señala Cordero, ya desde fines del siglo XIX se va produciendo un cambio en el centro de gravedad en el origen de las normas al interior del Estado, desde el Poder Legislativo al Ejecutivo, el cual absorbe una parte relevante de la producción normativa ${ }^{6}$. Desde la perspectiva de la estructura de la potestad normativa del legislador -que es lo que interesa analizar en esta sección- uno de los medios a través de los cuales ese cambio se gesta es por la utilización de la legislación no transitiva. De acuerdo a Rubin, se entiende por transitividad de la legislación el grado en que el legislador especifica los efectos que pretende que el mecanismo de implementación produzca sobre los $\operatorname{privados}^{7,8}$. En consecuencia, una disposición legal completamente transitiva es aquella que especifica la precisa regla a ser aplicada por el mecanismo de implementación; por el contrario, si una disposición legal se limita a instruirle al implementador que desarrolle reglas es enteramente intransitiva9 .

Dentro de la distinción entre legislación transitiva y no transitiva, es necesario subdistinguir entre transitividad en lo referido a la aplicación y en lo que concierne a la

\footnotetext{
${ }^{5}$ Para una referencia a los dilemas que se presentan en la sociedad de riesgos y una propuesta relativa a las herramientas para abordarlos, ver Sunstein, C., Riesgo y razón, Buenos Aires/Madrid, Katz editores S.A, 2006

${ }^{6}$ Cordero, E., "Los principios y reglas que estructuran el ordenamiento jurídico chileno", en Ius et Praxis, Vol. $15 \mathrm{~N}^{\circ} 2$ (2009), p. 16.

${ }^{7}$ Rubin, E., "Law and Legislation in the Administrative State", en Columbia Law Review, Vol. 89, N 3 , 1989 , p. 381.

${ }^{8}$ Para referirse a lo mismo, Kennedy habla de la realizabilidad de la Ley. Ver, Kennedy, D., "Form and substance in private law adjudication", en Harvard Law Review, Vol. 89, 1976, pp. 1687-1688.

${ }^{9}$ Rubin, E., "Law and Legislation in the Administrative State", en Columbia Law Review, Vol. 89, N³, 1989, p. 381.
} 
elaboración. Desde esta mirada, una ley se considera no transitiva desde la perspectiva de la aplicación cuando no especifica al mecanismo de implementación de la respectiva disposición la regla que espera que este último aplique al destinatario; simplemente le instruye que desarrolle esa regla ${ }^{10}$. Por el contrario, una disposición legal transitiva en cuanto a la aplicación establece, al menos, algunas reglas que la administración pública respectiva debe aplicar al privado. Sin embargo, las disposiciones legales de ese último tipo exhiben varios grados de transitividad en lo relativo a la manera en que estas reglas deben ser elaboradas por la administración ${ }^{11}$. Desde esta perspectiva, si la respectiva disposición legal se establece en términos demasiado amplios, no obstante su aplicabilidad directa, sigue siendo intransitiva, como por ejemplo lo es una disposición que se limita a establecer una sanción para "prácticas anticompetitivas". Así, desde la perspectiva de la aplicación, no existe tal cosa como una disposición totalmente transitiva, pues cualquier regla, sin importar cuán precisa sea, puede conllevar problemas interpretativos en su aplicación ${ }^{12}$.

En tanto característica estructural de la legislación, la no transitividad es un fenómeno que es posible apreciar en nuestro ordenamiento jurídico. Al respecto, el artículo 32 de la Ley $\mathrm{N}^{\circ} 19.300$ sobre Bases Generales del Medio Ambiente resulta un muy buen ejemplo. Lo anterior, debido a que esa norma legal establece las formalidades para promulgar normas de calidad, su ámbito de aplicación y la indicación que deberán establecer los niveles que originan situaciones de emergencia ambiental ${ }^{13}$. Acto seguido, la norma efectúa una remisión al reglamento para que éste establezca el procedimiento de dictación de normas de calidad ambiental, señalando que este último deberá considerar al menos las etapas de análisis técnico y económico; de desarrollo de estudios científicos de consultas a organismos competentes -ya sea públicos o privados-y de análisis de las observaciones formuladas, todo ello bajo una adecuada publicidad ${ }^{14}$. En definitiva, se aprecia que la aludida disposición no establece por sí misma la norma de calidad, siendo por ende no transitiva en cuanto a su aplicación. Sin embargo, y sin perjuicio de ello, entrega orientaciones sustantivas para su proceso de determinación, por lo que desde el punto de vista de la elaboración tiene bastantes grados de transitividad.
${ }^{10}$ Ibid.
11 Ibid.
12 Ibid.
${ }^{13}$ En la parte pertinente para este análisis, el inciso primero del artículo 32 de la Ley $\mathrm{N}^{\circ} 19.300$, sobre Bases Generales del Medio Ambiente, establece lo siguiente:

"Mediante decreto supremo, que llevará las firmas del Ministro del Medio Ambiente y del Ministro de Salud, se promulgarán las normas primarias de calidad ambiental. Estas normas serán de aplicación general en todo el territorio de la República y definirán los niveles que originan situaciones de emergencia”.

${ }^{14}$ Ver inciso cuarto del artículo 32 de la Ley No 19.300, sobre Bases Generales del Medio Ambiente:

"Un reglamento establecerá el procedimiento a seguir para la dictación de normas de calidad ambiental, que considerará a lo menos las siguientes etapas: análisis técnico y económico, desarrollo de estudios científicos, consultas a organismos competentes, públicos y privados, análisis de las observaciones formuladas y una adecuada publicidad. Establecerá además los plazos y formalidades que se requieran para dar cumplimiento a lo dispuesto en este artículo y los criterios para revisar las normas vigentes". 
Debido al dinamismo con el que se debe actuar, a fin de dar protección al respectivo bien jurídico, el legislador no se encuentra en una posición institucional privilegiada para tomar esa decisión, y eso bien lo sabe; sin perjuicio de ello, se asegura igualmente que la determinación que finalmente se adopte sea una razonable y consensuada. De ahí que en la propia Ley $\mathrm{N}^{\circ} 19.300$ se haya establecido que las normas de calidad deben actualizarse cada cinco años por la propia administración, pues está consciente de la variabilidad del objeto regulado y para otorgarle el nivel de protección adecuado estima necesario que se tomen decisiones con rapidez y de manera periódica ${ }^{15}$. No obstante lo anterior, también está consciente del alto contenido político de la decisión de establecer una norma de calidad ${ }^{16}$ y, por lo mismo, aparte de las exigencias mencionadas en el párrafo anterior, ordena que previo a su promulgación por parte del Ejecutivo éstas sean aprobadas por un cuerpo colegiado de carácter transversal, para así poder pesar adecuadamente todos los intereses que se encuentran en juego en esta decisión ${ }^{17}$. Así, como se puede apreciar, pese a que la regulación de las normas de calidad en la Ley $\mathrm{N}^{\circ} 19.300$ se realiza a través de una disposición no transitiva en cuanto a su aplicación, ello no implica que la regla que en definitiva se determine por la administración sea una en la que no se consideren las posturas de los diversos sectores e intereses, tal como ocurre en el proceso legislativo. A pesar de ello, todo esto puede fácilmente quedar en el olvido si la atención se centra únicamente en la naturaleza reglamentaria de la disposición que establece la respectiva norma de calidad; desde esta estrecha perspectiva, en cuanto la norma estaría abordando derechos fundamentales cuya regulación la Constitución reserva a la ley, podría ser inconstitucional. Es de esperar que haya quedado claro que el análisis debe ser bastante más complejo que uno de ese tipo.

El fundamento de la distinción entre legislación transitiva y no transitiva, cabe recalcarlo, es permitir a la ley cumplir su función social ${ }^{18}$. Ello, considerando que las virtudes de la transitividad tienen un alto costo: el sacrificio de la precisión en el logro de los objetivos que subyacen a la respectiva Ley ${ }^{19}$. En efecto, una mayor determinación en los términos de aplicación de una ley implica un menor margen de acción al momento de implementarla y esa restricción, a su vez, puede tornar imposible el cumplimiento

${ }^{15}$ Ver artículo 32 inciso 4 de la Ley $\mathrm{N}^{\circ} 19.300$.

${ }^{16}$ Bermúdez, J., Fundamentos de Derecho Ambiental, Ediciones Universitarias de Valparaíso, 2007, pp. 143 y ss.

${ }^{17}$ Ver artículo 71 letra f) de la Ley No 19.300. sobre Bases Generales del Medio Ambiente [Estableciendo la facultad del Consejo de Ministros para la Sustentabilidad de pronunciarse respecto a los proyectos de actos administrativos que se le presenten al Presidente de la República, que contengan normas de carácter ambiental]. Para una defensa de la transversalidad en la toma de decisiones en material de regulación y política ambiental, ver Sierra, L., "Reforma de la Institucionalidad Ambiental: Problemas y Oportunidades", en Estudios Públicos, Centro de Estudios Públicos [pdf] $\mathrm{N}^{\circ} 111,2008$, p. 59. Disponible online:<http://issuu.com/david.parra/docs/ rev111_lsierra_medioambiente? mode =embed\&documentId =081217204543-50fd2a4909b94cc892f75bd35 ba55cae\&layout $=$ white $>$ [Consulta: 13 de abril 2011].

18 Rubin, E., "Law and Legislation in the Administrative State", en Columbia Law Review, Vol. 89, N 3 , 1989 , p. 372.

19 Kennedy, D., "Form and substance in private law adjudication", en Harvard Law Review, Vol. 89, 1976, p. 1689 
de los objetivos de la respectiva ley en una circunstancia de hecho que no fue prevista, en su momento, por el legislador. Por lo mismo, la elección relativa a cómo estructurar una ley es una que debe ante todo tomarse en consideración a la manera más efectiva de lograr el objetivo querido por el legislador, en un supuesto de aplicación que será difícil de prever por anticipado ${ }^{20}$. Porque muchas veces, por las razones vistas, el legislador se inclina por dejar un margen de apreciación para el momento de la implementación, no puede seguir concibiéndose a la administración como un mero ejecutor exégeta de la voluntad legislativa, aspecto que analizaremos en el siguiente punto.

\subsection{El actual rol de la administración: algo más que la correa transmisora de la voluntad legislativa}

Situándose dentro de estas mismas coordenadas, cabe analizar el rol de la administración en la actualidad, el que se caracteriza por la necesidad de dar respuestas efectivas frente a una serie de problemas de política pública. Se ha señalado que la administración del Estado se encuentra atrapada entre el Scylla de la ilegitimidad y el Caribdis de la ineficiencia ${ }^{21}$. Sin embargo, la metáfora que por tanto tiempo buscó caracterizar a la administración, la de constituir una mera correa transmisora de directivas legislativas para la resolución de determinados casos, ha perdido desde hace un buen tiempo toda vigencia $^{22}$. No es que la administración haya dejado de transmitir la voluntad legislativa al ciudadano, sino más bien que su rol en la actualidad es bastante más amplio ${ }^{23}$. Hoy por hoy, la administración posee potestades normativas que cumplen la función de otorgarle un necesario margen de apreciación para hacer efectiva la voluntad legislativa, como asimismo para actuar en determinadas materias en procura de la mayor realización del bien público allí donde el legislador aún no lo ha hecho.

La distinción trazada por Rubin entre legislación transitiva y no transitiva es de utilidad para comprender este nuevo rol de la administración. En efecto, frente a ambos tipos de legislación a la administración le corresponde implementar la voluntad legislativa. Sin embargo, en la legislación no transitiva el legislador no establece regla alguna, sino que se limita a señalarle a la administración que desarrolle aquella regla que finalmente se le aplicará al destinatario. Así, el rol de la administración no es uno de mera aplicación y transmisión de una voluntad ajena, sino que, por el contrario, en atención a la expresa voluntad legislativa, allí donde existe legislación no transitiva la administración crea derecho; específicamente, la regla que se aplicará al destinatario final. Cuánto haya de crear, dependerá del grado de transitividad de la respectiva disposición;

${ }^{20}$ Rubin, E., "Law and Legislation in the Administrative State", en Columbia Law Review, Vol. 89, N 3 , 1989 , p. 418.

${ }^{21}$ Note, Deweyan Democracy and the Administrative State, en 125 Harvard Law Review, 2011, p. 582.

22 Stewart, R., "The reformation of American Administrative Law", en Harvard Law Review, Vol. 88, p. 1675.

${ }^{23}$ En el mismo sentido, Cordero, L., "Entre la deferencia, los estándares de control judicial y los procedimientos administrativos. Comentarios a las sentencias sobre el caso "Celco". Revista de Derecho Público No 68, 2005, p. 5. 
o, visto desde otra perspectiva, de cuánto de la implementación deje el legislador a la discrecionalidad de la administración.

La transitividad de una ley es la otra cara de la moneda de la discrecionalidad administrativa. Una disposición transitiva deja poco a la discrecionalidad de la administración; por el contrario, una no transitiva le deja bastante ${ }^{24}$. No está de más recordar por qué querría el legislador hacer esto: porque, a su juicio, es la mejor manera de que se cumpla con la finalidad de la respectiva ley. No obstante lo anterior, resulta notoriamente asimétrico el énfasis que ha puesto la doctrina en cada cara de la moneda; pues por obvio que resulte decirlo, muchísimo se habla de la discrecionalidad, pero o poco nada sobre la transitividad ${ }^{25}$. Para Rubin, este mayor énfasis en la discrecionalidad puede ser útil para una teoría de la administración o de interpretación de la ley, pero no logra proveer de una teoría acerca de la legislación; peor aun, centrarse en las Cortes como único mecanismo de implementación distorsiona el carácter de la legislación moderna, en la medida que éstas solo implementan legislación cuyo carácter es altamente transitivo ${ }^{26}$, en circunstancias que buena parte de la legislación que se dicta en la actualidad es, por el contrario, no transitiva.

Todas las reflexiones anteriores apuntan a reformular los límites que se establecen al reglamento de ejecución, pero, al menos explícitamente, en nada tocan al reglamento autónomo ${ }^{27}$, aunque no tendrían por qué no hacerlo. En tanto normativa general y abstracta, el reglamento autónomo, al igual que la ley y el reglamento de ejecución, está llamado a cumplir una determinada función. Ésta no es otra que abordar a través de normas ciertos aspectos de la vida social, en la medida que sea necesario para un adecuado gobierno y administración del Estado. Desde esta perspectiva, considerando la multiplicidad de situaciones que se dan en la vida social que demandan alguna disciplina normativa, el reglamento autónomo aparece en una posición privilegiada para abordarlos. Esta manera de concebir la potestad reglamentaria autónoma tiene sus raíces en una interpretación útil del texto constitucional: si la Constitución ha establecido una potestad reglamentaria autónoma es porque pretende que ella sea operativa.

El objetivo de la presente sección ha sido demostrar el cambio experimentado por la Ley y el Reglamento en el último tiempo. Para este propósito, se ha enfatizado la relevancia de la estructura de la legislación para articular su relación con las demás normas que componen el sistema de fuentes. Desde esta perspectiva, se ha analizado el rol de la legislación en la actualidad, enfatizando, desde el punto de vista de su estructura, que para poder cumplir con su función social debe tener ciertos grados de lo que Rubin denomina no transitividad. En directa vinculación a lo anterior, se ha analizado

${ }^{24}$ Rubin, E., "Law and Legislation in the Administrative State", en Columbia Law Review, Vol. 89, No 3 , 1989 , p. 383.

25 Ibid., p. 384.

${ }^{26}$ Rubin, Supra nota 14, pp. 384-385.

${ }^{27}$ Para mayores referencias sobre la potestad reglamentaria autónoma, ver Cordero, E., "El sentido actual del dominio legal y la potestad reglamentaria", en Revista de Derecho de la Universidad Católica de Valparaíso, Vol. 32, 2009, pp. 424-427. 
también el rol que le corresponde a la administración en nuestros días, dada la ineludible necesidad de implementar legislación no transitiva. En la próxima sección abordaré en qué términos debe redefinirse la reserva de ley para tomar en cuenta estas mutaciones en el rol de la Ley y el Reglamento; sugeriré además mecanismos a través de los cuales esa reserva de ley redefinida podría operar y, por último, abordaré las implicancias que tiene esta redefinición sobre la manera en que la adjudicación constitucional se aproxima a los casos de reserva legal.

\section{UNA PROPUESTA DE REDEFINICIÓN DE LA RESERVA LEGAL}

Una concreta redefinición de la reserva de ley, a mi juicio, debe abocarse a articular la colaboración entre Ley y Reglamento, encauzándola. Para servir ese propósito propongo algunos medios, como la remisión normativa y el establecimiento de objetivos en la Ley que guíen su implementación. Argumentaré que la redefinición propuesta no es incompatible con la Constitución; básicamente porque esta última no fija de manera precisa los contornos de la Ley y el Reglamento, ante lo cual hay buenas razones para aproximarse de manera deferente ante la interpretación que haga el legislador de este deslinde. Por último, cabe señalar que esta redefinición trae consecuencias para la adjudicación constitucional, la cual, para hacer sentido de ella, debe modificar su manera de aproximarse a los casos de reserva de ley. En términos específicos, esa aproximación, al menos para los casos en que se impugne la dictación de un reglamento de ejecución, pasa por poner en la balanza tres factores: (1) si la potestad reglamentaria ha abordado una materia sujeta a reserva, (2) la estructura del esquema regulatorio legal, en cuanto a su grado de transitividad, que ha sido ejecutado y, por último, (3) los finalidad que ha argumentado el Presidente para justificar la dictación del respectivo Reglamento.

\subsection{Los términos de la redefinición}

En la actualidad, como lo señala la doctrina más autorizada, la reserva de ley debe actuar como máxima de política legislativa, orientando la intensidad del trabajo del legislador hacia aquellas materias que la conforman ${ }^{28}$. Esto, sin embargo, no implica que en la ley misma se aborde todo lo relativo a esa materia sujeta a reserva. Más bien, considerando la necesidad de que la ley sea efectiva, lo relevante es que esta garantía encauce el ejercicio de la función legislativa hacia la articulación de mecanismos que permitan la colaboración entre Ley y Reglamento. En ese sentido, como ha sugerido Barnés $^{29}$, cuando el establecimiento de disposiciones sustantivas detalladas puede atentar en contra del cumplimiento de los objetivos de la respectiva ley, las exigencias

${ }^{28}$ Schmidt-Assmann, E., La teoría general del Derecho Administrativo como sistema, Marcial Pons/Instituto Nacional de Administración Pública, Madrid, 2003, p. 205.

${ }^{29}$ Barnés, J., "Towards a third generation of administrative procedures", en Rose-Ackerman, S. y Lindseth, P. (Eds.), Comparative Administrative Law, Edward Elgar Publishing, Vermont, 2010, p. 342. 
de la reserva de ley pueden satisfacerse a través de la articulación de procedimientos administrativos y de la estructura organizacional de las administraciones públicas que tomarán esas decisiones. Esta manera de proceder resguarda dos objetivos del más alto valor: (1) que el Parlamento, al orientar el ejercicio de la discrecionalidad administrativa, mantenga el control sobre las determinaciones que se adopten en las materias sujetas a reserva y (2) que exista una sustantiva colaboración entre Ley y Reglamento, que permita la eficacia de la legislación.

En este punto, habiendo entrado de lleno a la reserva de ley, el llamado es a redefinirla en los siguientes términos: como una institución que distribuya competencias entre el legislador y el Presidente de la República, sin que ello impida la colaboración entre la Ley y el Reglamento, para una mejor satisfacción de la función social de la primera. Podrá argumentarse que esa redefinición no es novedosa, sino que redundante, en cuanto la jurisprudencia y la doctrina, desde hace no poco tiempo, aluden a la colaboración entre Ley y Reglamento. La primera, de hecho, en el rol 254 de 1997 y en términos similares a los que se sugieren en este trabajo, ha llegado a señalar que "el otorgamiento al ejecutivo de facultades de ejecución resulta inevitable para el buen funcionamiento de la acción estatal" 30 . La segunda, en el trabajo del profesor y actual integrante del Tribunal Constitucional, Gonzalo García, ha dedicado una sección entera de un capítulo al punto de los fundamentos y condiciones de colaboración de la potestad reglamentaria ${ }^{31}$. En ambas subyace, sin embargo, una premisa que no comparto: que dentro del listado de materias contenidas en el artículo 63, la reserva es más absoluta cuando se refiere a reservas específicas, sobre todo a las que se establecen en la regulación constitucional de los derechos fundamentales.

Esa premisa, en no pocas situaciones, torna a la reserva de ley en una barrera para la colaboración ley-reglamento. En términos de la aludida distinción entre legislación transitiva y no transitiva, esa premisa implica afirmar que en aquellas materias donde la Constitución ha establecido reservas específicas las leyes que las regulen deben ser lo más transitivas que sea posible. En apariencia, al eliminar o reducir considerablemente la discrecionalidad en la implementación de esas disposiciones legales que regulan materias sujetas a reservas específicas, se asegura la protección de las mismas. Sin embargo, esa apreciación pierde de vista un factor que puede llevar a afirmar lo contrario: mientras más limitados los supuestos de aplicación de una disposición, más probable es que se vean superados por la realidad y, si eso es lo que sucede, menor va ser la protección que se le podrá otorgar al bien jurídico resguardado por la reserva. Como se argumentará en la sección relativa al Tribunal Constitucional, se requiere más que la intromisión reglamentaria en la disciplina normativa de una materia de dominio legal para estimar vulnerada la reserva legal; por ahora, sin embargo, basta con señalar que una teoría sobre

${ }^{30}$ STC 254/1997, considerando 18.

${ }^{31}$ García, G., "La Reserva Legal de Derechos Constitucionales: ¿Poder Legislativo contra la Administración?”, en Colección de Investigaciones Jurídicas, N 5, Universidad Alberto Hurtado, Santiago (2004), pp. 234 y ss. 
la colaboración ley-reglamento fundada en esa premisa impide o dificulta la aludida colaboración en una variedad de situaciones, haciendo necesario buscar otras alternativas.

\subsection{Los medios operativos de la redefinición}

Un primer medio que posibilita una amplia colaboración entre Ley y Reglamento o, si se quiere, el encauzamiento de la relación ley-reglamento es la remisión normativa. Es cierto que su constitucionalidad ha sido debatida tanto en doctrina ${ }^{32}$ como en la jurisprudencia ${ }^{33}$; no obstante que, como señala Correa $^{34}$, la sola lectura del artículo $7^{\circ}$ inciso 2 debiera despejar esas dudas, desde el momento en que dispone que aparte de la Constitución, la Ley también puede atribuir autoridad. Lo anterior, por cierto, no implica necesariamente, como lo ha sugerido entre nosotros Pierry ${ }^{35}$, que la remisión normativa abra la reserva a la administración, pero sí, al menos, que allí donde el legislador ha establecido una, el Tribunal Constitucional debe aproximarse, si no con deferencia, con respeto. Ese respeto se demuestra haciéndose la pregunta, en vez de descartarla como irrelevante desde una determinada concepción de la supremacía constitucional, de por qué y para qué el legislador optó por regular la respectiva cuestión a través de legislación no transitiva. Ahora bien, se sabe que la potestad reglamentaria de ejecución es discrecional y, en el mismo sentido, que existen varias leyes que más que utilizar remisiones normativas recurren a conceptos jurídicos indeterminados, por lo que se hace necesario adentrarse en el análisis de cómo se da la colaboración ley-reglamento en disposiciones de ese tipo.

En aquellas situaciones en que se presenta la necesidad de ejecutar la ley y ésta no da instrucciones a la administración sobre cómo implementarla o bien lo hace a través de conceptos jurídicos indeterminados, puede darse igualmente la colaboración leyreglamento, aunque sobre la base de otros parámetros establecidos en la ley, como lo son, por ejemplo, sus objetivos. De acuerdo a Rubin, no existe una conexión necesaria entre la legislación orientada a objetivos y la discrecionalidad administrativa, desde el momento que un objetivo ambicioso puede constituir un límite mucho más poderoso sobre ésta que el uso de lenguaje específico ${ }^{36}$. La situación que mejor ilustra este punto es la de una disposición altamente específica queda obsoleta; como es fácil de advertir, muy poco va a ser lo que ella podrá orientar el ejercicio de la discrecionalidad administrativa $^{37}$. Adicionalmente, el establecimiento de objetivos en la legislación proporciona

32 Soto Kloss, E., "En la forma que prescriba la ley: notas sobre prácticas legislativas inconstitucionales". En Revista Chilena de Derecho, Vol. 20, Nos 2 y 3, 1991, pp. 690- 691, Pierry, P., "El ámbito de la ley", en El proceso legislativo en Chile (AA. VV.), CEAL-UCV, Valparaíso, 1991, p. 85.

33 Por ejemplo, STC 185/1994, STC 253/1997, STC 370/2003, STC 1710/2010.

${ }^{34}$ Correa, R.,"Tribunal Constitucional”, en Revista de Derecho, Universidad Adolfo Ibáñez, No 1, 2004, p. 482.

35 Pierry, P., "El ámbito de la ley", en El proceso legislativo en Chile (AA. VV.), CEAL-UCV, Valparaíso, 1991, p. 85 .

${ }^{36}$ Rubin, E., "Law and Legislation in the Administrative State", en Columbia Law Review, Vol. 89, $\mathbf{N}^{\circ} 3$, 1989, p. 412.

37 Ibid., p. 414. 
un parámetro de suma utilidad para el control del ejercicio de las atribuciones que confiere $^{38}$. De esta forma, puede evidenciarse cómo el establecimiento de objetivos en la legislación puede servir como parámetro para la colaboración ley-reglamento, sin que ello necesariamente implique quedar a merced de una discrecionalidad administrativa incontrolable.

Estas reflexiones proporcionan argumentos para defender una concepción amplia de la colaboración ley-reglamento en el ejercicio de la potestad reglamentaria de ejecución, colaboración que también puede darse eventualmente, aunque de manera opuesta, en el ejercicio de la potestad reglamentaria autónoma.

Aun cuando la potestad reglamentaria autónoma debe ejercerse en materias que no se enmarcan dentro del dominio legal, eso no impide que luego de su ejercicio puedan darse relaciones de colaboración entre la Ley y el Reglamento. En efecto, el ejercicio de la potestad reglamentaria autónoma, siempre y cuando el legislador con posterioridad estime que se trata de una materia que requiere de una regulación más estable, puede gatillar que la materia sea abordada por una ley, dándose de esta manera entre Ley y Reglamento una relación de colaboración invertida. De hecho, el ejemplo de la regulación de la firma digital -abordada por primera vez en un reglamento autónomo y luego por una ley, para la aplicación de la cual se dictó con posterioridad un reglamento de ejecución-, que recurrentemente es citado por la doctrina para demostrar que la potestad reglamentaria autónoma no es la norma de clausura en nuestro ordenamiento jurídico ${ }^{39}$, es ilustrativo también de esta relación de colaboración invertida. En definitiva, del hecho de que la potestad reglamentaria autónoma no sea la norma de clausura en nuestro ordenamiento jurídico, no se sigue su inutilidad; ella muchas veces puede ilustrar al legislador aspectos que hasta ahora no ha considerado y que pueden ser dignos de abordar mediante legislación. En el intertanto, porque se ha ejercido esta potestad, los ciudadanos cuentan con reglas en la materia, lo que no es poco.

\subsection{La compatibilidad de la redefinición con la Constitución}

El primer -y quizás más importante- argumento que puede esgrimirse a favor de la plena compatibilidad de la Constitución con la redefinición propuesta es que no contradice la normativa de distribución de competencias entre Ley y Reglamento contenida en la Constitución. En relación a ésta, se ha señalado que la capacidad normativa de ambas fuentes es variable, no quedando establecidos con claridad los campos competenciales, ni menos los límites, del dominio legal y de la potestad reglamentaria ${ }^{40}$. De

${ }^{38}$ Ibid., pp. 414-415.

${ }^{39}$ Cazor, K., La sumisión a derecho de los actos y disposiciones del Presidente de la República. La potestad jurídica presidencial y el sistema de control aplicable como garantía del Estado constitucional, TI, Universidad Central de Chile, Santiago, 2002, p. 171, y Cordero, E., "El sentido actual del dominio legal y la potestad reglamentaria", en Revista de Derecho de la Universidad Católica de Valparaíso, Vol. 32, 2009, p. 427.

${ }^{40}$ Cazor, K. y Pfeffer, E., "La búsqueda de criterios orientadores en la configuración de las potestades normativas en Chile”, en Ius et Praxis, Vol. 15 N 1 (2009), p. 192. 
ahí que, como ha constatado la doctrina, no baste con revisar la aludida disposición para determinar cuáles son las materias de ley ${ }^{41}$, en cuanto su consagración se hace de forma variable, con distintas intensidades ${ }^{42}$, por lo que para hacer sentido de esta diversidad de materias e intensidades regulativas se han elaborado diversas sistematizaciones del catálogo contenido en la aludida disposición ${ }^{43}$. También se ha analizado por la literatura la cuestión específica de cómo la normativa de distribución de competencias incide sobre la potestad reglamentaria autónoma y la de ejecución ${ }^{44}$. Respecto a la primera, se ha dicho que debido a la utilización en el artículo 63 de conceptos jurídicos indeterminados en el numeral 20, queda vacía de contenido; mientras que en lo referido a la segunda, se ha dicho que en la Constitución no quedan claros los límites de la función de regulación -perteneciente, en principio, a la Ley-, como tampoco aquellos de la función de ejecución, correspondiente al Reglamento ${ }^{45}$. Como se puede apreciar, existe coincidencia en la reciente literatura sobre la inexistencia de límites claros y, por tanto, de campos competenciales definidos entre el dominio legal y la potestad reglamentaria, por lo que, prima facie, no existe un límite preciso que pudiese estar siendo eventualmente traspasado por este entendimiento más amplio de la colaboración entre Ley y Reglamento.

Sin embargo, aun de estimarse que las materias sujetas a reserva deben abordarse por el legislador, tampoco existiría incompatibilidad con la redefinición que acá planteo, pues una cuestión es que la ley deba necesariamente abordar ciertas materias, otra, y bien distinta, es que ésta sea la única que pueda hacerlo. La sola lectura de la parte final del artículo $32 \mathrm{~N}^{\circ}$ 6, que autoriza al Presidente para dictar los reglamentos para la ejecución de las leyes cuando estime conveniente, descarta la idea de un dominio exclusivo y excluyente del legislador sobre la respectiva materia. Si esto es así, el asunto debe ser entendido como lo hace De Otto, en términos de sectores correspondientes a la Ley y al Reglamento en la disciplina normativa de un determinado asunto ${ }^{46}$. El deslinde entre uno y otro sector, al menos en nuestra Constitución Política, no es uno que quede claro; ante esta ambigüedad, la pregunta es: ¿qué interpretación habrá de preferirse, aquella que realicen los poderes democráticamente legitimados o la del órgano no democráticamente legitimado que tiene a su custodia la Constitución? Aunque con un mayor recelo en el escrutinio tratándose de la interpretación del Ejecutivo, la primera parece ser la mejor alternativa.

41 Pierry, P., "El ámbito de la ley”, en El proceso legislativo en Chile (AA. VV.), CEAL-UCV, Valparaíso, 1991, p. 78.

42 Cordero, E., "El sentido actual del dominio legal y la potestad reglamentaria", en Revista de Derecho de la Universidad Católica de Valparaíso, Vol. 32, 2009, p. 415.

43 Silva, A., "La jerarquía normativa en la Constitución de 1980", en Revista de Derecho Universidad Católica de Valparaíso, Vol. 6 (1982), pp. 115 y ss.; Pierry, P., "El ámbito de la ley”, en El proceso legislativo en Chile (AA. VV.), CEAL-UCV, Valparaíso, 1991, p. 78.

${ }^{44}$ Cordero, E., "Los principios y reglas que estructuran el ordenamiento jurídico chileno", en Ius et Praxis, Vol. $15 \mathrm{~N}^{\circ} 2$ (2009), p. 23.

45 Ibid.

${ }^{46}$ De Otto, I., Derecho Constitucional. Sistema de fuentes, Ariel, Barcelona, 1987, p. 236. 
La legitimación democrática del Parlamento, estimo, obliga a intentar hacer sentido de su opción por el uso de disposiciones no transitivas. El objetivo básico del legislador al dictar una ley es siempre el mismo: que esa ley sea efectiva ${ }^{47}$. Para lograr ese propósito el legislador deberá evaluar, entre otras cuestiones, si en consideración a las características de la materia y al contexto en el cual habrá de aplicarse, es o no conveniente usar disposiciones más o menos transitivas. Si estima que lo más conveniente para que la ley sea efectiva es la utilización de disposiciones no transitivas; el intérprete constitucional debiera darle algún nivel relevante de peso argumentativo a esa determinación. Afirmar lo contrario, esto es, que la ambiguamente definida reserva de ley prima por sobre la opción de esquema regulatorio del legislador, además de negarle el juicio soberano sobre el punto, priva a la legislación un medio muy relevante para el ejercicio de su función.

Esta misma lógica, aun cuando con ciertos matices, debiera aplicarse para aquellos casos en los que, sin que exista un esquema regulatorio tan claramente articulado a favor de la flexibilidad, el Presidente de la República dicte un reglamento de ejecución. En lo que se está pensando es en aquellos supuestos en los que la ley no abordó un asunto sujeto a reserva; o, si lo hizo, esto fue llevado a cabo a través del recurso a un concepto jurídico indeterminado. Nuevamente, analizar por qué el Presidente ejerció su potestad es relevante; la más probable respuesta a ello es porque existía, a su juicio, la necesidad pública de ejecutar la ley. No está de más recordar, a estas alturas, el fundamento de esta potestad: permitirle al Presidente de la República contar con autosuficiencia normativa, de manera tal que pueda ejecutar las leyes y administrar el Estado ${ }^{48}$, dotándolo consiguientemente de un poder excepcional de creación concurrente del orden jurídico, para poder cumplir su rol constitucional de Jefe de Gobierno y de la Administración del Estado $^{49}$. Desde esta perspectiva, si acaso existía o no esa necesidad, es una decisión que típicamente corresponde a aquel órgano que se le reconoce la facultad y el deber asociado de gobernar y administrar el Estado. Ahora, por cierto que en una hipótesis como esta, dada la inexistencia de resguardos estructurales que sí están presentes para el caso del legislador, a esta argumentación se le debe asignar un peso argumentativo menor del que se ha señalado respecto del legislador, aun cuando está lejos de ser insignificante.

Habiendo establecido en la sección anterior las razones que justifican redefinir la función de la reserva de ley, lo que se ha hecho en ésta es explicar para qué finalidad específica debe procederse a esa redefinición y referirse de manera muy somera a los medios que pueden ser utilizados para ello. En relación a la finalidad, he señalado que no es otra que permitir la colaboración ley-reglamento; darle plena operatividad. Para ese propósito, dependiendo del nivel de transitividad de la ley a ejecutar, he propuesto dos medios: la remisión normativa -para el caso de las disposiciones con mayores

${ }^{47}$ Rubin, E., "Law and Legislation in the Administrative State", en Columbia Law Review, Vol. 89, N 3 , 1989 , p. 409.

${ }^{48}$ Cordero, E., "El sentido actual del dominio legal y la potestad reglamentaria", en Revista de Derecho de la Universidad Católica de Valparaíso, Vol. 32, 2009, p. 416.

${ }^{49}$ Ferrada, J. C., "Las potestades y privilegios de la administración pública en el régimen administrativo chileno", en Revista de Derecho, Universidad Austral, Vol. 20, N², 2007, p. 78. 
grados de transitividad, desde el punto de vista de la elaboración- y el establecimiento de los objetivos de la ley- para aquellas hipótesis de disposiciones no transitivas, desde la perspectiva de la elaboración y la aplicación. Para las hipótesis de ejercicio de la potestad reglamentaria autónoma, he argumentado que también puede producirse la colaboración con la ley, aunque de manera invertida, a aquella que se da en la potestad reglamentaria de ejecución. Esta redefinición, así como los medios que se proponen para su implementación son plenamente compatibles con la Constitución y debieran ser considerados en la adjudicación constitucional; sin embargo, para que eso suceda, el Tribunal Constitucional debe modificar su manera de aproximarse a los casos de reserva legal, cuestión que desarrollaré a continuación.

\subsection{Implicancias para la adjudicación constitucional}

Para el Tribunal Constitucional, el control de decretos supremos ha sido una actividad recurrente. Como lo detalla una de las últimas investigaciones realizadas sobre la materia por Carlos Carmona, actual Ministro del Tribunal Constitucional, los parlamentarios han utilizado de manera intensa la posibilidad que les franquea la Constitución de presentar requerimientos impugnando la constitucionalidad de decretos supremos ${ }^{50}$. En efecto, desde el retorno de la democracia hasta la fecha de término de la citada investigación, se habían presentado 24 requerimientos ${ }^{51}$, cifra que es significativa respecto del total de casos, excluyendo los requerimientos de inaplicabilidad ${ }^{52}$. Sin embargo, la habitualidad con que el Congreso ejerce esta actividad no ha traído como consecuencia una mayor consistencia en la fundamentación de las sentencias.

Justicia del $\operatorname{cadî}^{53}$ y reserva de sentencia son, de hecho, algunos de los calificativos que ha utilizado la literatura para caracterizar la poco consistente jurisprudencia desarrollada por el Tribunal Constitucional en la materia. En una primera etapa, dicha jurisprudencia se mostró reacia a la intervención del reglamento en las materias sujetas a reserva $^{54}$. Luego, sin perjuicio que flexibilizó su postura al respecto, siguió evidenciando una cierta hostilidad hacia el ejercicio de la potestad reglamentaria en las materias sujetas a reserva. En términos específicos, aceptando la posibilidad de que el Reglamento interviniera en las materias sujetas a reserva, el Tribunal Constitucional centró su análisis en la intensidad de esta intervención, ${ }^{55}$ partiendo, de manera más o menos explícita,

${ }^{50}$ Carmona, C., "El artículo 93 N 16 de la Constitución: estado de la cuestión y proyecciones”, en Revista de Derecho Público, Vol. 72, 2010, p. 56.

51 Ibid.

52 Ibid.

53 Zúñiga. F., “Apostillas: Ley y Reglamento a la Jurisprudencia del Tribunal Constitucional (De la germanización al practicismo), en Ius et Praxis, Vol. 7, N², 2001, pp. 209-257.

${ }^{54}$ Carmona, C., "Un nuevo estadio en la relación ley-reglamento: el ámbito del reglamento", en Revista de Derecho Público, Vol. 63, 2001, pp. 154-155.

55 Carmona, C., "Tres problemas de la potestad reglamentaria: legitimidad, intensidad y control", en Revista de Derecho Consejo de Defensa del Estado, Vol. 3, 2001. 
de la premisa de que en aquellas materias relativas a derechos fundamentales solo era posible una intervención de baja intensidad ${ }^{56}$. En la jurisprudencia de los últimos años, si bien no se discute la posibilidad misma de intervención de la potestad reglamentaria en materias sujetas a reserva, esa desconfianza hacia la intervención del reglamento en éstas ha llevado al desarrollo de una jurisprudencia altamente casuística, en la que los tests elaborados por el propio Tribunal no se aplican consistentemente e incluso, si la fundamentación del resultado lo requiere, se crean unos nuevos ${ }^{57}$.

Ahora bien, si se considera la manera en que la Constitución regula la distribución de competencias en la materia entre el legislador y el Ejecutivo, esa inconsistente y altamente casuística adjudicación no es para nada sorprendente. Como señalé en la primera parte de este trabajo, el alcance de la ley y la potestad reglamentaria en sus dos vertientes no queda del todo determinado en la Constitución. De ahí que al Tribunal Constitucional le cueste mantener la consistencia al adjudicar casos sobre esta temática; es que respecto a una cuestión cuya regulación no es clara, iluso resulta pensar que la adjudicación operará de manera consistente. Ello, pues una vez que se acepta la intervención del reglamento en esquemas regulatorios que abordan materias sujetas a reserva ${ }^{58}$, la cuestión relativa a hasta qué punto puede llegar el reglamento es una de grado, que no puede resolverse sino por referencia a los hechos concretos del caso en donde se presenta la cuestión. El casuismo a la hora de embarcarse en la empresa de establecer las fronteras entre la potestad normativa del legislador y aquella de la administración, cabe señalarlo, es algo que trasciende nuestras fronteras.

En efecto, establecer una línea divisoria entre lo que es el ejercicio de funciones legislativas y ejecutivas, es el cometido en que se propone la doctrina nondelegation en el derecho de Estados Unidos. Ésta impone límites sobre la autoridad del Congreso de delegar el Poder Legislativo, en consideración a que la Constitución se lo ha otorgado de manera íntegra a este órgano; específicamente, que toda delegación a la administración debe contener un principio inteligible -un estándar-, para orientar el ejercicio de la discrecionalidad administrativa de la respectiva administración pública ${ }^{59}$. La referida

\section{STC 370/2003.}

${ }^{57}$ Ese parece ser el caso de los fallos ISAPRES y TV Digital. Si se quisiese articular un hilo coherente, este sería que, aun cuando el TC acepta que el Reglamento intervenga en la regulación de materias sujetas a reserva, esa aceptación parece ser menor a la que existía hace algún par de años. Razonamiento que demuestra el hecho de que en ISAPRES, no obstante no tratarse de un caso de potestad reglamentaria de ejecución sino de ejercicio de potestad normativa estatutaria por parte de un órgano descentralizado, el TC haya estimado vulnerada la reserva en relación a una materia en la cual la exigencia constitucional es más laxa, y que en TV Digital, el TC, para fundamentar la no vulneración, no haya articulado estándar teórico alguno que explique esa decisión -por sí solo, el hecho de que el Presidente ejerza la potestad reglamentaria con miras al bien común no es estándar alguno. Ver, STC 1710/2010 y STC 1849/2010.

${ }^{58}$ Esto es, en términos de Carmona, una vez que en la jurisprudencia del Tribunal Constitucional sobre reserva de ley se abandona el estadio de la legitimidad y se pasa al de la intensidad. Ver Carmona, C., "Un nuevo estadio en la relación ley-reglamento: el ámbito del reglamento”, en Revista de Derecho Público, Vol. 63, 2001, pp. 154-155.

${ }^{59}$ Ver Stone, G., Seidman, L., Sunstein, C., Tushnet, M., Karlan, P., Constitutional Law. Aspen Publishers, New York, 2005, p. 418. 
doctrina se aplicó para invalidar remisiones normativas tan sólo dos veces y en un contexto muy particular: la constitucionalmente conflictiva instalación del New Deal ${ }^{60}$. La explicación a la escasa aplicación de dicha doctrina la proporciona, en términos más que elocuentes, el actual Juez de la Corte Suprema, Antonin Scalia, para quien "[a]un cuando la cuestión de la delegación inconstitucional es, sin duda alguna, un elemento fundamental de nuestro sistema constitucional, no es un elemento que se preste para ser implementado por las Cortes" 61 . En consideración a la dificultad que presenta esta doctrina para su aplicación por las Cortes, en vez de centrar su análisis en la naturaleza de la potestad ejercida, la jurisprudencia de la Corte Suprema de Estados Unidos lo ha hecho en el ejercicio concreto de la misma, verificando si estaba autorizado por ley y si el resultado del mismo es una interpretación permisible de la respectiva ley ${ }^{62}$. El abandono de la doctrina nondelegation en Estados Unidos y su posterior sustitución por un control de ejercicio de la respectiva actuación de la administración debiera traer luces a la adjudicación constitucional en materia de reserva de ley en Chile, en los siguientes sentidos: (1) ilustrando lo difícil que resulta para las Cortes controlar únicamente sobre la base de parámetros formales y (2) demostrando que la actuación de la administración puede ser controlada perfectamente utilizando parámetros funcionales, que asumen la necesidad de la colaboración entre Ley y Reglamento.

Es posible divisar una adjudicación constitucional en la materia que opere sobre parámetros más funcionales a la colaboración ley-reglamento. Un primer paso para ello es asumir que la intensidad con la que el reglamento interviene en la disciplina normativa de una materia sujeta a reserva no es el único factor a considerar. Además de éste, se pueden tomar en cuenta otros dos factores que junto al anterior debieran balancearse a la hora de resolver un caso sobre reserva de ley: el grado de transitividad del esquema regulatorio que se está ejecutando y la finalidad pública argumentada por el Ejecutivo para justificar la dictación de la respectiva disposición reglamentaria. La utilización de estos dos nuevos elementos como aspectos a ponderar junto al de la intensidad del reglamento en su intervención en materias sujetas a reserva de ley permite que el Tribunal adjudique asumiendo la realidad de la Ley y el Reglamento en la actualidad. Por supuesto que los hechos del caso tendrán una incidencia determinante sobre cuánto pese cada uno de estos tres elementos y que, consecuentemente, seguirán existiendo casuismo e inconsistencia; pero al menos, este esquema garantiza que ese casuismo e inconsistencia se hagan cargo de los aspectos funcionales de la colaboración ley-reglamento.

Por último, cabe hacer referencia a cómo debiera ser la adjudicación de casos originados en la dictación de reglamentos autónomos. El aspecto crucial para el análisis de esta cuestión es el dato bruto que dichos reglamentos al no referirse a materias de ley no suponen la existencia de una norma legal que pueda ser utilizada como parámetro

${ }^{60}$ Ver, Panama Refining Co. v. Ryan, 293 U.S. 388 (1935) y A.L.A. Schechter Poultry Corp. v. United States, 295 U.S. 495 (1935).

61 Ver Mistretta v. United States, 488 U.S. 361 (1989), Voto de minoría del Juez Antonin Scalia.

${ }^{62}$ Chevron U.S.A. Inc. v. Natural Resources Defense Council, Inc., 467 U.S. 837 (1984). 
para su control. Tan sólo está la determinación del Ejecutivo en torno a la necesidad de disciplinar una determinada materia que, a su juicio, no se encuentra incluida dentro de aquellas que la Constitución sujeta a reserva. Por lo mismo, sólo se debe considerar si acaso la potestad reglamentaria autónoma ha incursionado en una materia de ley. Aun cuando esta determinación requiere de un análisis que comprende menos elementos que los que he sugerido para el reglamento de ejecución, no deja de ser compleja, dados los indeterminados contornos de la reserva de ley en nuestra Constitución.

\section{Conclusiones}

Al concluir el presente análisis no está de más destacar nuevamente la importancia de la efectividad de la legislación. Como señala Rubin, la inefectividad en la administración es también un abuso ${ }^{63}$. Desde esta perspectiva, a la hora de establecer esquemas regulatorios para la protección de determinados bienes jurídicos cobra relevancia la elección legislativa en torno a cómo estructurar las disposiciones de una ley para asegurar su eficacia. De esa opción depende el margen de apreciación que tendrá la administración al momento de implementarla. Frente a la elección del grado de transitividad de una disposición legislativa, debiera tener algo que decir la reserva de ley. Pero que deba tener algo que decir no significa que ella deba ser ciega frente a la pretensión de efectividad de la legislación.

Es que el análisis relativo a la reserva legal no debe limitarse a la cuestión de quién decide sobre un aspecto relativo a una materia de ley, sino que también debe considerar cómo se hace efectiva la voluntad legislativa en la materia sujeta a reserva. Desde esta perspectiva, una aproximación al fenómeno de la reserva de ley que no se refiera a ambas cuestiones no está abordando el problema en su globalidad. En el mismo sentido, aquellas que aluden a la implementación, pero exigen como requisito la utilización de lenguaje específico, para facilitar la posterior revisión judicial, tampoco se hacen cargo del problema. Hace ya bastante tiempo que las Cortes dejaron de ser las únicas que implementan el derecho. Consecuentemente, la opción legislativa por un determinado mecanismo de implementación y el juicio del Ejecutivo en torno al momento de aplicarlo también son relevantes para la reserva legal, si se considera que ella debe velar por encauzar la vinculación entre la legislación y su implementación mediante el Reglamento.

Es cierto que la incorporación de más variables o factores a la ecuación, en un área donde con las ya existentes se hace complejo resolver los casos, puede tornar aun más inciertas las cosas en la materia. Sin embargo, no se debe perder de vista que sean cuáles sean los criterios que guíen su aplicación, los parámetros constitucionales son bastante imprecisos. Por lo mismo, a pesar de lo valioso que puede ser la consistencia en la aplicación de las disposiciones constitucionales, esta es un área donde no cabe

${ }^{63}$ Rubin, E., "Law and Legislation in the Administrative State", en Columbia Law Review, Vol. 89, $\mathrm{N}^{\circ} 3$, 1989 , p. 418. 
esperarla. Más que lamentarse o buscar una fórmula mágica de adjudicación que termine con la inconsistencia, lo razonable es asumirla y proponer metodologías que permitan la articulación de una mejor fundamentación. Eso es, precisamente, lo que se busca con la incorporación de estos dos factores al análisis de decretos supremos que se impugnen por vulnerar la reserva legal.

En suma, la protección de la vigencia de los derechos fundamentales reconocidos en nuestra Constitución se vería seriamente reducida si la única vía de implementarlos fuera a través de las Cortes. Esta constatación debe llevar necesariamente a la conclusión de que se necesita legislación no transitiva. Ella es la mejor alternativa para el cumplimiento de la función de la legislación. Por supuesto, eso no quiere decir que no deba quedar sujeta a control, pero éste, a diferencia de lo que sucede en la actualidad, no debiera partir desde la desconfianza. Como exactamente llevarlo a cabo, si se parte de la premisa de la necesidad de la legislación no transitiva, es un importantísimo desafío al cual sin duda se debe apuntar en el futuro.

\section{BIBLIOGRAFÍA}

Aldunate, E., "La distribución de potestades normativas en la Constitución: potestades reglamentarias administrativas, autos acordados y facultades del fiscal nacional”, en Revista de Derecho de la Pontificia Universidad Católica de Valparaíso, 2009.

BARnÉs, J., "Towards a third generation of administrative procedures”, en Rose-Ackerman, S. y Lindseth, P., (Eds.), Comparative Administrative Law, Edward Elgar Publishing, Vermont, 2010.

Bermúdez, J., Fundamentos de Derecho Ambiental, Ediciones Universitarias de Valparaíso, 2007.

Bulnes, L., "Leyes de base y potestad reglamentaria en la Constitución de 1980", en Revista de Derecho de la Pontificia Universidad Católica de Valparaíso, vol. 6, 1982.

Carmona, C., "Un nuevo estadio en la relación ley-reglamento", en Revista de Derecho Público, vol. 63.

Carmona, C., "Tres problemas de la potestad reglamentaria: legitimidad, intensidad y control", en Revista de Derecho Consejo de Defensa del Estado, Vol. 3, 2001.

Carmona, C., "El artículo 93 N 16 de la Constitución: estado de la cuestión y proyecciones", en Revista de Derecho Público, Vol. 72, 2010.

Cazor, K., La sumisión a derecho de los actos y disposiciones del Presidente de la República. La potestad jurídica presidencial y el sistema de control aplicable como garantía del Estado constitucional, TI, Universidad Central de Chile, Santiago, 2002.

Cazor, K., "Nuevo artículo $93 \mathrm{~N}^{\circ}$ 16: Un enfoque más coherente en torno al control de los decretos supremos por parte del Tribunal Constitucional”, en Zúñiga F. (coord.), Reforma constitucional, Editorial LexisNexis, Santiago, 2005.

Cazor, K. y Pfeffer, E., "La búsqueda de criterios orientadores en la configuración de las potestades normativas en Chile", en Ius et Praxis, Vol. $15 \mathrm{~N}^{\circ} 1$ (2009).

CEA, J. L., "Dominio legal y reglamentario en la Constitución de 1980", en Revista Chilena de Derecho, Vol. 11, 1984.

Cordero, E., "Los principios y reglas que estructuran el ordenamiento jurídico chileno", en Ius et Praxis, Vol. $15 \mathrm{~N}^{\circ} 2$ (2009).

Cordero, E., "El sentido actual del dominio legal y la potestad reglamentaria", en Revista de Derecho de la Pontificia Universidad Católica de Valparaíso, Vol. 32, 2009. 
Cordero, E., "Las normas administrativas y el sistema de fuentes", en Revista de Derecho Universidad Católica del Norte, año $17, \mathrm{~N}^{\circ} 1$,

Cordero, L., "Entre la deferencia, los estándares de control judicial y los procedimientos administrativos. Comentarios a las sentencias sobre el caso Celco", en Revista de Derecho Público, Vol. 68, 2006.

Correa, R., “Tribunal Constitucional”, en Revista de Derecho, Universidad Adolfo Ibáñez, N 1, 2004.

De Otтo, I., Derecho Constitucional. Sistema de fuentes, Ariel, Barcelona, 1991, 315 p.

FerradA, J. C., "Las potestades y privilegios de la administración pública en el régimen administrativo Chileno", en Revista de Derecho, Universidad Austral, Vol. 20, N 2, 2007.

Fermandois, A., "La reserva legal: una garantía sustantiva que desaparece”, en Revista Chilena de Derecho, Vol.28 N², 2001.

García, G., "La Reserva Legal de Derechos Constitucionales: ¿Poder Legislativo contra la Administración?", en Colección de Investigaciones Jurídicas, $\mathrm{N}^{\circ}$ 5, Universidad Alberto Hurtado, Santiago, 2004.

Kennedy, D., "Form and substance in Private Law adjudication", en Harvard Law Review, Vol. 89, 1976.

MoragA, C., "La actividad formal de la administración del Estado”, en Pantoja, R. (Coord), Tratado de Derecho Administrativo, Tomo VII, Santiago, 2010.

, Notes, Deweyan Democracy and the Administrative State, en Harvard Law Review, 2011.

Pierry, P., "El ámbito de la ley”, en AA. VV, El Proceso Legislativo en Chile, CEAL-UCV, Valparaíso, 1991.

Rajevic E., "Limitaciones, reserva legal y contenido esencial de la propiedad privada”, en Revista Chilena de Derecho, vol. 23, N 1, 1996.

Ribera, T., "Reserva legal y potestad reglamentaria en la Constitución de 1980", en Revista de Derecho Público, vol. 63, 2001.

Rubin, E., "Law and Legislation in the Administrative State", en Columbia Law Review, Vol. 89, $\mathrm{N}^{\circ}$ 3, 1989.

Schmidt-Assmann, E., La teoría general del Derecho Administrativo como sistema, Marcial Pons/ Instituto Nacional de Administración Pública, Madrid, 2003.

Sierra, L., "Reforma de la Institucionalidad Ambiental: Problemas y Oportunidades", en Estudios Públicos, Centro de Estudios Públicos [pdf] N $\mathrm{N}^{\circ} 111,2008$, p. 59.

Silva, A., "La jerarquía normativa en la Constitución de 1980", en Revista de Derecho Universidad Católica de Valparaíso, Vol. 6, 1982.

Silva, E., Derecho Administrativo Chileno y Comparado. Introducción y fuentes, Editorial Jurídica, Santiago, Cuarta Edición, 1996.

Sunstein, C., "Riesgo y razón”, Buenos Aires/Madrid, Katz editores S.A, 2006.

Soто KLoss, E., "En la forma que prescriba la ley: notas sobre prácticas legislativas inconstitucionales”, en Revista Chilena de Derecho, Vol. 20, N² y 3, 1991.

STEWART, R., "The reformation of American Administrative Law", en Harvard Law Review, Vol. 88.

Stone, G., Seidman, L., Sunstein, C., Tushnet, M. y Karlan, P., Constitutional Law, Aspen Publishers, New York, 2005.

ZúÑIGA, F., “Apostillas: Ley y Reglamento en la Jurisprudencia del Tribunal Constitucional (De la germanización al practicismo)", en Revista Ius et Praxis, Vol. 7, N², (2001). 


\section{JURISPRUDENCIA}

Tribunal Constitucional, Rol Nº 185 (1994).

Tribunal Constitucional, Rol N² 254 (1997).

Tribunal Constitucional, Rol No 370 (2003).

Tribunal Constitucional, Rol No 1710 (2010).

Tribunal Constitucional, Rol Nº 1849 (2010).

Corte Suprema de Estados Unidos: Panama Refining Co. v. Ryan, 293 U.S. 388 (1935).

Corte Suprema de Estados Unidos: A.L.A. Schechter Poultry Corp. v. United States, 295 U.S. 495 (1935).

Corte Suprema de Estados Unidos: Chevron U.S.A. Inc. v. Natural Resources Defense Council, Inc., 467 U.S. 837 (1984).

CoRTe Suprema de Estados Unidos: Mistretta v. United States, 488 U.S. 361 (1989). 
